\title{
PROFESSIONAL DEVELOPMENT OF SECONDARY SCHOOL TEACHERS: ASSOCIATING THINKING STYLE PROFILES AND INSTRUCTIONAL PRACTICES
}

\author{
Abdul Qayyum $^{1 *}$, Sidra Rizwan ${ }^{2}$, Nasir Mahmood ${ }^{3}$ \\ ${ }^{1 *} \mathrm{Ph} . \mathrm{D}$, Scholar, Allama Iqbal Open University, Islamabad, Pakistan; ${ }^{2}$ Lecturer, Allama Iqbal Open University, Islamabad, \\ Pakistan; ${ }^{3}$ Dean, Faculty of Education, Allama Iqbal Open University, Islamabad, Pakistan. \\ Email: ${ }^{1 *}$ qayyum.hmd@ gmail.com, ${ }^{2}$ sidra.rizwan@aiou.edu.pk, ${ }^{3}$ nasir.mahmood@aiou.edu.pk \\ Article History: Received on $15^{\text {th }}$ April 2021, Revised on $10^{\text {th }}$ May 2021, Published on $18^{\text {th }}$ May 2021
}

\begin{abstract}
Purpose of the study: The study aimed to find the association between teachers' thinking style profile types (TSPT-I, II, and III) instructional practices (IPs) at the secondary school level in Pakistan.

Methodology: The sample of the study was 550 teachers in public sector schools of district Sialkot. Thinking style inventory (TSI-RII) based on a 7-point Likert type scale was used to collect data for the identification of (TS). Frequency distribution and Pearson chi-square were used to analyze the data.
\end{abstract}

Main Findings: The results revealed that the teachers in (TSPT-I) preferred using Concept Accomplishment, Simulations, cooperative Learning, Homework, and Reinforcement, whereas teachers in (TSPT-II)Rich Vocabulary, Lecturing, Daily Assessment, Concept Accomplishment, and teachers in(TSPT-III)Cooperative Learning, Rich Vocabulary, Reinforcement, Simulations, and Daily Assessment as a set of (IPs).

Application of the study: This study may help the teacher trainers and school principals to understand the thinking styles of the teachers and their preferences for the certain set of instructional practices to focus the preferences of the teachers according to their thinking style profiles to save time and money.

Novelty/Originality of this study: Teacher training programs are conducted on the assumption that all the teachers can be trained uniformly regardless of their preferences for instructional practices. But this study has shown the association between thinking style profiles and set of instructional practices and secondary school level.

Keywords: Professional Development, Thinking Style, Profile Types, Instructional Practices, Secondary School Teachers.

\section{INTRODUCTION}

Professional development of the teachers plays a significant role to meet the modern needs of education. Scientific innovations have changed the entire face of the world. Now teachers need to be well trained and well equipped to meet the requirements of the world around them. A lot of time and money is spent on the teacher training programs without paying much attention to the purpose for which it is being imparted. In Pakistan, a lot of time and money is spent on the training of professional development of the in-service teachers on the assumption that all the teachers can be trained uniformly regardless of their preferences or interests in a specific area of teaching. Previous studies show that teachers' thinking style affects the teaching practice in the classroom. If an association is established between (TSPTs) and (IPs) used in the classroom it may help the teacher trainers to organize and design teacher training programs for professional development to focus on specific sets of (IPs) for certain (TSPTs). It will save a lot of time and financial resources and increase the effectiveness of the professional development programs for the in-service teachers

Thinking is a human quality that is shown by actions. It refers to the patterns of behavior consistent over a long period of having many areas of activity. The term style refers to distinct and characteristic manner or habitual pattern of doing something in solving tasks and face situations (Medwel \& Wray, 2018). Thinking style refers to use or exploit intelligence and knowledge together. It, notability rather it is the use of the ability to solve the problems in daily life. Earlier style models presented only some specific dimension of style rather than covering all the dimensions. To cover the previous shortcomings Sternberg (1997) proposed the theory of mental-self-government in which he integrated all the previous thinking style theories. He used the word government metaphorically arguing that as there are different kinds of ways to govern a society, people use their abilities in the same ways and these preferences can be constructed as thinking styles. Later the theory was used in the education field.

The theory specifies 13 thinking styles consisted of five dimensions: 3 functions, four forms, two levels, two scopes, and two leanings. In the way of looking at things, the styles in this theory are cognitive. In the context of the use of preferences of abilities, these styles look personality-centered, in activity-centered tradition; these styles can be measured in the context of activities. 
In the education field, teachers' thinking styles may contribute to teaching in the classroom. Thinking styles may change from task to task and situation to situation, age, experience, gender, and location, etc. of the teachers. Thinking styles are not exclusive. A teacher may use more than one thinking style but there will be one predominant thinking style. The combination of more than one thinking style is called a thinking style profile.

Zhang and Sternberg (2005) recommended a three-fold model of thinking styles. Thirteen thinking styles were grouped into three types i.e. Type-1, Type-2, and Type-3 thinking style profiles. Type-1 thinking style profile consisted of creativity generating and signifies a high level of cognitive complexity. Type-2 thinking style profile (Zhang \& Sternburg, 2005) signifies the low level of cognitive complexity and has a norm favoring tendency. Type-3 thinking style profile (Zhang, 2003) may comprise of both the characteristics of Type- 1 and Type- 2 thinking styles manifesting the demand of the situation or task under consideration in the classroom. These thinking style profiles have integrated previous models e.g., five easy to monitor dimensions of preferences for problem-solving and these are teachers' predilections for the high degree of structure to the low degree of structure, cognitive simplicity to cognitive complexity, conformity to non-conformity, the authority to autonomy and group to individual work. Empirical evidence and conceptualization (Zhang \& Postigilion, 2001) show that most of the styles are value-laden or value differentiated rather than value-free. These styles have trait-like and state-like aspects as these styles are modifiable and overlap across the theories.

Type-1 thinking style profile is related to creative attributes and tends to carry out more adaptive values. Type- 2 thinking style profile consists of a low degree of freedom and is strongly related to undesirable attributes. Due to a high level of contingency, Type-3 thinking style profile may have sometimes more or sometimes have less adaptive value depending upon the task or situation in the classroom.

The thinking style of the teacher may contribute to the use of instructional practices in the classroom. (Budijanto, 2013) revealed that match and mismatch of the teacher's thinking style and students' thinking style affects the teaching-learning process in the classroom. The results show that the match between thinking styles of both teacher and student contributes better use of instructional practices in the classroom. Empirical studies by (King \& Watson, 2010; Mushtaq, 2013) revealed that the focused teacher training programs may produce more effective results as compared to the uniform training programs.

(IPs) are strategies that a teacher uses in the classroom to achieve maximum learning outcomes. Cues, Concept accomplishment, brainstorming, Effectiveness, Jigsaw, Cooperative Learning, Rich Vocabulary, Lecturing, Socratic Seminar, Daily assessments, Simulations, Homework, use of Real Objects, and Reinforcement (CTAC \& WCSD, 2015; $\underline{\mathrm{SRC}, 2011)}$.

\section{Significance of the Study}

This study may contribute to understanding (TSPT-I, II, and III) and learning to adopt certain sets and patterns of (IPs) within each (TSPTs) used by the teachers in the classroom. The role of teachers' thinking style signifies that the perception of the thinking style profiles may facilitate and enhance the possibility of better interaction through instructional practices in the classroom.

This study may find the relationship between thinking style profiles and instructional practices, thus if we know the instructional practices of teachers, we can easily determine their thinking style profiles or vice versa. An understanding of teachers' (TSPT-I, II, and III) and the use of (IPs) in the classroom may provide school principals an insight into the knowledge of solving the problems, more analytical, and adaptive about teachers' preferences of (IPs). Principals of the schools may also empower the teachers in developing and strengthening their expertise and proficiency according to their (TSPTs) to use their potential by allowing freedom in the use of (IPs) in the classroom.

The awareness and knowledge of teachers having different (TSPTs) and use of their specific set of (IPs)may also be beneficial in guiding the in-service teachers to understand their thinking style profiles and use a particular set of instructional practices suitable to their (TSPT-I, II, and III). It may also help the teacher trainers in deciding different components of training according to the (TSPT-I, II, and III) of teachers and sets of (IPs) they preferably use while teaching.

\section{Statement of the Problem}

Generally, uniform teacher training for all the teachers in Pakistan is designed and conducted for the in-service teachers for their professional development of teachers regularly. It is generally designed on the assumption that all the teachers require the same type of training regardless of their preferences. Without knowing the preferences and existing skills of the teachers, training is arranged. Empirical studies showed that training for in-service teachers remains ineffective and resources are wasted on this frantic exercise across the country. The training is not the cause behind this ineffectiveness, but it is the method with which the training is designed, and imparted and teacher training is not equally useful for all the participating teachers that fail to achieve the required objectives. 


\section{The objective of the Study}

1. To describe the level of (TSPT-I, II, and III) of secondary school teachers.

2. To describe the level of instructional practices of secondary school teachers.

3. To find out the relationship between teachers' thinking style profiles and set off their (IPs) at the secondary school level.

\section{LITERATURE REVIEW}

Different variables beyond the abilities affect the teachers' teaching in the classroom. Teachers' instructional practices may reveal their thinking styles and thinking styles are preferences to express abilities (Devine, Fahie, \& McGillicuddy, 2013; OECD, 2015). Teachers thinking styles tend to match the stylistic patterns of the students may lead to an effective teachinglearning process. In the field of education, many researchers have contributed to the thinking styles of the teacher and teachers' interaction with the students in the classroom which may affect the instructional practices of the teachers in the classroom.

In the field of education, regarding styles, Curry (1983) presented three-layer models: The innermost layer consists of measures of personality, the middle layer is composed of information processing measures and the upper layer comprises measures of teachers' preferences to use instructional practices in the classroom. Miller's (1987) model comprising individual differences, cognitive processes, and styles. This model further categorized information processing into nine individual styles. The learning approach has a surface, deep, and achieving levels. Realistic, investigative, artistic, social, conventional, and enterprising are career personality styles. Analytical, holistic and investigative are modes of thinking. Extroversion, introversion, sensing, intuitive, thinking, feeling, judging, and perceiving is personality style types. Mindstyle consists of abstract random approach, concrete-sequential approach, abstract-sequential, and trial-and-error approach. Innovative and adoptive are decision-making styles. Reflective and impulsive are conceptual styles, divergent and convergent are the structure of intellect, Field independent and Field dependent is perceptual styles of thinking. Riding and Cheema's (1991) model was based on the two dimensions: verbal imagery and holistic -analytic approach. An empirical study by Riding and Rayner (1998) revealed that cognitive style dimensions are associated with subject preferences, learning performance, and learning preferences, occupational behavior, conduct behavior, and the physical well-being of the teachers.

Sternberg (1997) in his theory of mental self-government summed up all the previous theories of styles in the education field. Thinking styles are psychological, cognitive, sociological, physiological, and effective. Thinking styles are effective because teachers' way of using instructional practices and dealing with the situation and tasks in the classroom may be determined by their thinking styles. Thinking styles are psychological because human senses i.e., hearing touch, and vision influence the information provided to the teachers. Thinking styles are psychological because these styles are contingent upon how teachers react to the situation in the classroom. Thinking styles are sociological because these are affected by preferences used by the teachers in the classroom.

Zhang and Sternberg (2005) in the threefold model grouped thirteen thinking styles of the theory of mental self-government into three profile types, type-I thinking style profile, Type-II thinking style profile, and Type-III thinking style profile (Zhang, 2003) relate to the three issues regarding whether thinking styles have trait vs state characteristics or are value-laden or value-free (Zhang \& Postiglion, 2001). Trait or state line of research explored the relationship of teachers' thinking styles and their teaching beliefs. It focused on their stability and flexibility of teachers' thinking styles over time. Several crosssectional studies indicated that teacher thinking styles vary with age, gender, location, experience, qualification, socioeconomic status, and stylistic patterns of the environment. To understand the issue that whether the thinking styles are valueladen or value-free (Zhang, 2003) revealed in an empirical study that the teachers' having thinking styles that are creative and require a higher level of complexity and degree of freedom are: Legislative, Judicial, and Global, hierarchical and liberal thinking styles. According to (Fer, 2012) 27 empirical studies revealed that there is a significant relationship between the thinking style (TS) of the gender of the teachers, and 14 studies showed that there is no significant relationship between the gender of the teachers at the secondary school level. Male and female teachers using instructional practices at secondary school level living in rural and urban areas are the variables of this study for two reasons: Previously studies were conducted outside Pakistan, and those studies were to test the hypothesis for (TS), but the present study was conducted in Pakistan and to test the hypotheses for (TSPs) to see whether the hypothesis is true for both (TS) and (TSPs) for male and female teachers at secondary school level living in the rural and urban areas. In Pakistan, there is a lot of diversity in the population. Social taboos hinder women to avail, even, prevailing opportunities in the field of education as compared to the male part of the population having access to all the resources (Hussain, Reddy \& Kamil, 2018). Due to lack of education congested educational environment, they are not well aware of their rights and maybe a difference in their (TS) as they have to face problems differently while using instructional practices in the classrooms as compared to male teachers. Female teachers are less social and have a greater inclination to be conventional and traditional and follow the established rules and regulation 
instead of using such activities demanding more independence and critical thinking, but male teachers may have a greater propensity to be more independent pragmatic, and investigative (Watson, Foxcroft, \& Allen, 2007).

Gender distinction creates very grave problems as Pakistan is a male-dominated society where female teachers must survive in a restricted environment. On the other hand, male teachers have a more comfortable environment to work in. Females are sent to school under great restriction and even they are not sent to schools and if they are sent to school, they get fewer chances to complete their education. This gravity increases increase in rural areas of Pakistan. The urban-rural divide in Pakistan is $28 \%-72 \%$. There is a lot of difference in terms of rural-urban facilities in all spheres of life, but its magnitude of this gap increases in the field of education. But there is no difference in terms of recruitment policies and education policies. Environment affects teachers' thinking style. Teachers' thinking styles may affect the (IPs) in the classroom Ho \& Maroof $\underline{(2009)}$.

Teachers face a simpler and more natural environment in rural life than congested urban life. Large families live together and share the facilities and problems of each other. They are more cooperative and tolerant, and the family system is still very strong in understanding each other's problems. Due to financial constraints and lack of educational facilities teachers adjust their instructional practices according to the task and requirements of the situation. Available facilities, the nature of the task, and the situation faced by the teachers may change due to location. Orientation for the use of (IPs) may be affected the (TSPs) of the teachers at the secondary school level.

The level of the educational environment in rural areas is lower than the educational environment in urban areas. Teachers do not take the educational activities very gravely as the parents of the students are mostly uneducated or not well aware of the needs of their children and unable to provide educational assistance and give feedback to the instructional process at school on the other hand parents in urban areas are mostly literate and aware of the educational innovations and ask for implementations of new ideas and activities in the classrooms. The teachers have to focus on the requirements of the subject of study and use such instructional practices which fulfill the modern needs of society (Hussain, Reddy \& Kamil, 2018). To avoid a lot of prevailing knowledge and safe time, teachers must focus certain sets of instructional practices suits to their (TSPs) to achieve maximum learning from the students. Teachers' preferred way to adopt (IPs) for the interaction with the students is a powerful force that may manipulate them for better learning outcomes in the classroom at the secondary school level (Zhu, 2013). Preferred Instructional practices used by the teachers are closely linked with the (TSPs) of the teachers. Teachers use (IPs) according to the tasks and situations the teachers may face in the classroom. Teachers'(TSPs)is the preferred way of using the ability to select certain sets of (IPs) while teaching and may change from situation to situation, experience, qualification, subject, age, location, and gender, of the teacher (Zhang, 2016).

(IPs) used by the teachers may be affected by the tasks or situations faced by the teachers in the classroom. The efficiency of use of (IPs) may also vary from grade to grade, subject to subject, student's background, socioeconomic background of the students, and teachers' (TSPs) (Marzano, \& Pickering, 2007).

Instructional practices may be the results of teachers' self-reflection and required situations and need-based tasks of teachercentred, student-centred, peer-reflection, and participation level of both teachers and the students in the classroom. (IPs) are used and cast off, and controlled by the teachers to attain the maximum learning output from the students (Ribas, 2005). (IPs) are strategies that teachers use in the classroom to achieve maximum learning outcomes. Cues, Concept accomplishment, brainstorming, Effectiveness, Jigsaw, Cooperative Learning, Rich Vocabulary, Lecturing, Socratic Seminar, Daily Assessment, Simulations, Homework, use of Real Objects, and Reinforcement were the commonly (IPs) used in the classroom (CTAC \& WCSD, 2015; $\underline{\text { SRC, 2011). }}$

Literature review revealed that the (IPs) of teachers relate to their (TSPTs). The knowledge of thinking styles of the teachers helps to establish the (IPs) of teachers. Teachers (TSPTs) show their preferred certain sets of certain (IPs) and they may have proficiency in these (IPs) according to their interests. If an association is ascertaining between teachers' (TSPTs) and (IPs) it may help to design teacher training programs according to the (TSPTs) of teachers to further reinforce their preferred sets of (IPs). Therefore, this study aimed to find out the relationship between (TSPTs) of teachers and sets of their preferred (IPs) in the classroom at the secondary school level.

\section{Hypotheses}

$\mathbf{H o}_{1}$ : There is no significant relationship between (TSPT-I) and observed (IPs).

$\mathrm{Ho}_{2}$ : There is no significant relationship between (TSPT-II) and observed (IPs).

Ho $:$ There is no significant relationship between (TSPT-III) and observed (IPs). 


\section{METHODOLOGY}

The study was descriptive. The questionnaire of thinking style inventory revised (TSR- R2) adopted from (Sternberg, Wagner, \& Zhang, 2007) and self-developed observation schedule was used to collect data by using a cross-sectional design. A stratified random sampling technique was used to take a sample. The sample included male-female urban and rural areas. The data were collected through a questionnaire constructed on 7- points Likert-type scale. The teachers were classified into 13 thinking styles and through a self-developed observation schedule, eighteen teachers were observed and aligned with the (IPs) used by the teacher in the classroom. There was no need to check the reliability of the questionnaire thinking style inventory revised (TSR- R2) as it was an adopted tool. Axial coding was used to develop the self-developed observation schedule. The reliability of the self-developed observation schedule was checked in terms of Krippendorffalpha (Hayes \& Krippendorff, 2007) which was satisfactory (.834). Pearson Chi-Square was applied to analyze the data.

\section{Population}

The population of the study constituted all the teachers teaching at the secondary level in district Sialkot. 4986 teachers were teaching at the secondary school level including male-female living in urban and rural areas.

The population of the study was as follows:

Table 1: Tehsil wise Gender and Location of Secondary Teachers of district Sialkot

\begin{tabular}{llllll}
\hline \multicolumn{2}{l}{ Male Teachers } & \multicolumn{2}{l}{ Female Teachers } & Total \\
\hline Tehsil & Urban & Rural & Urban & Rural & \\
\hline Sialkot & $353(7 \%)$ & $658(13 \%)$ & $218(4 \%)$ & $477(10 \%)$ & $1706(34 \%)$ \\
\hline Daska & $167(4 \%)$ & $491(10 \%)$ & $163(3 \%)$ & $505(10 \%)$ & $1326(27 \%)$ \\
\hline Sambrial & $57(1 \%)$ & $281(6 \%)$ & $55(1 \%)$ & $304(6 \%)$ & $697(14 \%)$ \\
\hline Pasrur & $93(2 \%)$ & $503(10 \%)$ & $107(2 \%)$ & $554(11 \%)$ & $1257(25 \%)$ \\
\hline Total & $670(14 \%)$ & $1933(39 \%)$ & $543(10 \%)$ & $1840(37 \%)$ & $4986(100 \%)$ \\
\hline
\end{tabular}

Source: School Education Department, Government of Punjab

\section{Sample of the Study}

The sample of the study constituted 550 teachers male292 (urban77, rural 215) and female 258(urban55, rural 203). The teachers were selected through stratified random sampling.

The sample of the study was as follows:

Table 2: Stratified proportionate sample of the study

\begin{tabular}{llllll}
\hline Tehsil & \multicolumn{4}{l}{ Male Teachers } & \multicolumn{2}{l}{ Female Teachers } \\
\hline & Urban & Rural & Urban & Rural & Total \\
\hline Sialkot & 39 & 72 & 22 & 5 & 187 \\
\hline Daska & 22 & 55 & 16 & 55 & 148 \\
\hline Sambrial & 5 & 33 & 6 & 33 & 77 \\
\hline Pasrur & 11 & 55 & 11 & 60 & 138 \\
\hline Total & 77 & 215 & 55 & 203 & 550 \\
\hline
\end{tabular}

\section{Data Analysis}

To achieve the first objective and address the first question of the study the teachers were grouped into (TSPT-I, II, and III) Frequency distribution was used to analyze the data.

Table 3: Teachers having Thinking Style Profiles Type-I, II and III(N=416)

\begin{tabular}{lll}
\hline Thinking style profiles Type I & Frequency & Percent \\
\hline Legislative & 30 & $20.3 \%$ \\
\hline Judicial & 54 & $36.5 \%$ \\
\hline Hierarchic & 17 & $11.5 \%$ \\
\hline Global & 18 & $12.1 \%$ \\
\hline Liberal & 29 & $19.6 \%$ \\
\hline Total & 148 & $100.0 \%$ \\
\hline Thinking style profiles Type II & & \\
\hline Executive & 42 & $32.8 \%$ \\
\hline
\end{tabular}




\begin{tabular}{lll}
\hline Monarchic & 13 & $10.2 \%$ \\
\hline Local & 33 & $25.8 \%$ \\
\hline Conservative & 40 & $31.2 \%$ \\
\hline Total & 128 & $100.0 \%$ \\
\hline Thinking style profiles Type III & & \\
\hline Oligarchic & 28 & $20.0 \%$ \\
\hline Anarchic & 18 & $12.9 \%$ \\
\hline Internal & 36 & $25.7 \%$ \\
\hline External & 58 & $41.4 \%$ \\
\hline Total & 140 & $100.0 \%$ \\
\hline
\end{tabular}

Source: Authors’' Own Work

Table 3 reveals that out of 416,148 teachers were identified as (TSPT-I) which comprised of Legislative, Judicial, Hierarchical, Global, and Liberal (TS). In (TSPT-I), 38(21.3\%) teachers had Legislative, 62(34.8\%) had Judicial, 37(20.8\%) had Hierarchic, 20 (11.2\%) had Global, and 21(11.8) teachers had Liberal (TS).

Table 3 further reveals that out of 416, 128 teachers were having (TSPT-II) constituted Executive, Monarchic, local, and Conservative (TS). In (TSPT-II), 51(32.9\%) teachers had Executive, 46(29.7\%) had Monarchic 17(11.0\%) had local, and 41(26.5\%) teachers had Conservative (TS).

Moreover, table 3 also reveals that (TSPT-III) consisted of Oligarchic, Anarchic, Internal, and External (TS). In (TSPT-III), 33(19.8\%) teachers were having Oligarchic, 23(13.8\%) having Anarchic, 44(26.3\%) Internal and 67 (40.1\%) teachers were having External thinking style. Tables1, 2, and 3 showed the identification of the teachers into respective (TSP-I, II, and III), and thus the second objective of the study was achieved.

To address the second question that which instructional practices are predominantly used by the secondary school teachers? Frequency distribution was used to analyze the data.

Table 4: Sets of Dominating Instructional Practices according to Thinking StyleProfiles

\begin{tabular}{llll}
\hline Sr. No & $\begin{array}{l}\text { Thinking style Profile } \\
\text { (TSP) }\end{array}$ & Instructional Practices & Frequency \\
\hline & Type I* & \\
\hline 1 & & Concept Accomplishment & 76 \\
\hline 2 & & Simulations & 76 \\
\hline 3 & Cooperative Learning & 60 \\
\hline 4 & Homework & 43 \\
\hline 5 & Reinforcement & 36 \\
\hline & Type II** & Rich Vocabulary & 95 \\
\hline 1 & & Lecturing & 92 \\
\hline 2 & & Daily Assessment & 56 \\
\hline 3 & Concept Accomplishment & 56 \\
\hline 4 & Reinforcement & 38 \\
\hline 5 & & & 64 \\
\hline 1 & Type III*** & Cooperative Learning & 56 \\
\hline 2 & & Rich Vocabulary & 55 \\
\hline 3 & Reinforcement & 51 \\
\hline 4 & Simulations & 48 \\
\hline 5 & Daily Assessment \\
\hline
\end{tabular}

*Legislative, Judicial, Global, Hierarchic, and Liberal

**Executive, Local, Monarchic, and Conservative

***Oligarchic, Anarchic, Internal, and External

Source: Authors' Work 
Table 4 reveals that the dominating (IPs) for (TSPT-I) were Concept Accomplishment (76), Simulations (76), Cooperative Learning (60), Homework (43), and Reinforcement (36).

Table 4 further reveals that the dominating (IPs) for (TSPT-II) were Rich Vocabulary (95), Lecturing (92), Daily Assessment (56), Concept Accomplishment (56), and Reinforcement (38).

Moreover, the table 4 also reveals that dominating (IPs) for (TSPT-III) were cooperative Learning (64), Rich Vocabulary (56), Reinforcement (55), Simulations (51), and Daily Assessment (48).

To achieve the second objective and verify the hypothesis "There is no significant relationship in the set of instructional practices of teachers having different Types of thinking style profiles" the Pearson Chi-Square was applied to analyze the data.

$\mathbf{H}_{01}$ : There is no significant relationship between (TSPT-I) and observed (IPs).

$\mathbf{H}_{\mathbf{0 2}}$ : There is no significant relationship between (TSPT-II) and observed (IPs).

$\mathbf{H}_{03}$ : There is no significant relationship between (TSPT-III) and observed (IPs).

Table 5: Relationship between (TSP) Type-I and observed Instructional Practices

\begin{tabular}{|c|c|c|c|c|c|}
\hline \multirow[t]{5}{*}{ Thinking Style Profile Type I } & \multicolumn{3}{|c|}{ Instructional Practices } & \multicolumn{2}{|c|}{ df $\quad$ Pearson Chi-Square } \\
\hline & \multicolumn{3}{|c|}{ Concept Accomplishment } & & \multirow{4}{*}{$\begin{array}{l}8.471 \\
p=.014\end{array}$} \\
\hline & count & No & Yes & & \\
\hline & Observed & 0 & 24 & 2 & \\
\hline & Expected & 1.3 & 22.7 & & \\
\hline \multirow{3}{*}{ Legislative } & Simulation & & & \multirow{3}{*}{2} & \multirow{3}{*}{$\begin{array}{l}37.895 \\
\mathrm{P}=.000\end{array}$} \\
\hline & Observed & 0 & 24 & & \\
\hline & Expected & 5.0 & 19.0 & & \\
\hline Judicial & \multicolumn{3}{|c|}{ Cooperative Learning } & \multirow{3}{*}{2} & \multirow{3}{*}{$\begin{array}{l}18.000 \\
p=.000\end{array}$} \\
\hline \multirow[t]{2}{*}{ Global } & Observed & 4 & 20 & & \\
\hline & Expected & 5.3 & 18.7 & & \\
\hline Hierarchic & Homeworl & & & \multirow[t]{3}{*}{2} & \multirow{3}{*}{$\begin{array}{l}11.029 \\
\mathrm{P}=.021\end{array}$} \\
\hline \multirow{5}{*}{ Liberal } & Observed & 1 & 23 & & \\
\hline & Expected & 1.3 & 22.7 & & \\
\hline & \multicolumn{3}{|c|}{ Reinforcement } & 2 & \multirow{3}{*}{$\begin{array}{l}7.510 \\
p=.010\end{array}$} \\
\hline & Observed & 0 & 24 & & \\
\hline & Expected & 2.0 & 22.0 & & \\
\hline
\end{tabular}

Source: Authors' Own Work

Table 4 reveals the:

\section{Relationship between (TSPT-I) and (IP) Concept Accomplishment}

$\chi 2=8.471, \mathrm{df}=2, \mathrm{p}=.014$ indicates that the $\mathrm{p}$-value is less than $\alpha=.05$ i.e. there is a significant relationship between (TSPT-I) and Concept accomplishment as (IP). Thus rejecting the null hypothesis i.e. there is no significant relationship between (TSPT-I) and observed (IP) Concept accomplishment.

\section{Relationship between (TSPT-I) and (IP) Simulations}

$\chi 2=37.895, \mathrm{df}=2, \mathrm{p}=.000$ indicates that the $\mathrm{p}$-value is less than $\alpha=.05$ i.e. there is a significant relationship between (TSPT-I) and Simulations as an (IP). Thus rejecting the null hypothesis i.e. there is no significant relationship between (TSPT-I) and observed (IP) Simulations.

\section{Relationship between (TSPT-I) and (IP) Cooperative Learning}

$\chi 2=18.000, \mathrm{df}=2, \mathrm{p}=.000$ indicates that the $\mathrm{p}$-value is less than $\alpha=.05$ i.e. there is a significant relationship between (TSPT-I) and cooperative Learning as an (IP). Thus rejecting the null hypothesis i.e. there is no significant relationship between (TSPT-I) and observed (IP) Cooperative Learning. 


\section{Relationship between (TSPT-I) and (IP) Homework}

$\chi 2=.529, \mathrm{df}=2, \mathrm{p}=.021$ indicates that the $\mathrm{p}$-value is less than $\alpha=.05$ i.e. there is a significant relationship between (TSPT-I) and Homework as an (IP). Thus rejecting the null hypothesis i.e. there is no significant relationship between (TSPT-I) and observed (IP) Homework.

\section{Relationship between (TSPT-I) and (IP) Reinforcement}

$\chi 2=3.273, \mathrm{df}=2, \mathrm{p}=.010$ indicates that the $\mathrm{p}$-value is less than $\alpha=.05$ i.e. there is a significant relationship between (TSPT-I) and Reinforcements an (IP). Thus rejecting the null hypothesis i.e. there is no significant relationship between (TSPT-I) and observed (IP) Reinforcement.

Table 6: Relationship between (TSP) Type- II and observed Instructional Practices

\begin{tabular}{|c|c|c|c|c|c|}
\hline \multirow[t]{5}{*}{ Thinking Style Profile Type II } & \multicolumn{3}{|c|}{ Instructional Practices } & \multicolumn{2}{|c|}{ df Pearson Chi-Square } \\
\hline & \multicolumn{3}{|c|}{ Rich Vocabulary } & \multirow{4}{*}{2} & \multirow{4}{*}{$\begin{array}{l}6.503 \\
p=.039\end{array}$} \\
\hline & count & No & Yes & & \\
\hline & Observed & 6 & 22 & & \\
\hline & Expected & 3.3 & 20.7 & & \\
\hline \multirow{3}{*}{ Executive } & Lecturing & & & \multirow{3}{*}{2} & \multirow{3}{*}{$\begin{array}{l}22.400 \\
\mathrm{p}=.000\end{array}$} \\
\hline & Observed & 11 & 18 & & \\
\hline & Expected & 9.0 & 15.0 & & \\
\hline \multirow{2}{*}{ Local } & Daily Asses & ment & & \multirow{3}{*}{2} & \multirow{3}{*}{$\begin{array}{l}14.500 \\
p=.039\end{array}$} \\
\hline & Observed & 4 & 23 & & \\
\hline \multirow{2}{*}{ Monarchic } & Expected & 2.7 & 21.3 & & \\
\hline & Concept A & comp & hment & \multirow{3}{*}{2} & \multirow{3}{*}{$\begin{array}{l}8.471 \\
p=.014\end{array}$} \\
\hline \multirow{5}{*}{ Conservative } & Observed & 0 & 24 & & \\
\hline & Expected & 1.3 & 22.7 & & \\
\hline & Reinforcem & & & \multirow{3}{*}{2} & \multirow{3}{*}{$\begin{array}{l}7.510 \\
p=.010\end{array}$} \\
\hline & Observed & 0 & 24 & & \\
\hline & Expected & 2.0 & 22.0 & & \\
\hline
\end{tabular}

Source: Authors' Own Work

Table 5 reveals the:

\section{Relationship between (TSPT-II) and (IP) Rich Vocabulary}

$\chi 2=6.503, \mathrm{df}=2, \mathrm{p}=.039$ indicates that the $\mathrm{p}$-value is less than $\alpha=.05$ i.e. there is a significant relationship between (TSPT-II) and Rich Vocabulary as an instructional practice. Thus rejecting the null hypothesis i.e. there is no significant relationship between (TSPT-II) and observed (IP) Rich Vocabulary.

\section{Relationship between (TSPT-II) and (IP) Lecturing}

$\chi 2=22.400, \mathrm{df}=2, \mathrm{p}=.000$ indicates that the $\mathrm{p}$-value is less than $\alpha=.05$ i.e. there is a significant relationship between (TSPTII) and lecturing as an (IP). Thus rejecting the null hypothesis i.e. there is no significant relationship between (TSPT-II) and observed (IP) Lecturing.

\section{Relationship between thinking (TSPT-II) and (IP) Daily Assessment}

$\chi 2=4.500, \mathrm{df}=2, \mathrm{p}=.039$ indicates that the $\mathrm{p}$-value is greater than $\alpha=.05$ i.e. there is a significant relationship between (TSPTII) and daily Assessments (IP). Thus rejecting the null hypothesis i.e. there is no significant relationship between (TSPT-II) and observed (IP) Daily Assessment.

\section{Relationship between (TSPT-II) and (IP) Concept Accomplishment}

$\chi 2=8.471, \mathrm{df}=2, \mathrm{p}=.014$ indicates that the $\mathrm{p}$-value is less than $\alpha=.05$ i.e. there is a significant relationship between (TSPT-II) concept Accomplishment as and (IP). Thus rejecting the null hypothesis i.e. there is no significant relationship between (TSPT-II) and observed (IP) Concept Accomplishment

\section{Relationship between (TSPT-II) and (IP) Reinforcement}

$\chi 2=3.273, \mathrm{df}=2, \mathrm{p}=.010$. It indicates that the $\mathrm{p}$-value is less than $\alpha=.05$ i.e. there is a significant relationship between (TSPT- 
II) and Reinforcement as an (IP). Thus rejecting the null hypothesis i.e. there is no significant relationship between (TSPT-II) and observed (IP) Reinforcement.

Table 7: Relationship between (TSP) Type -III and observed Instructional Practices

\begin{tabular}{|c|c|c|c|c|c|}
\hline \multirow[t]{3}{*}{ Thinking Style Profile Type III } & \multicolumn{3}{|c|}{ Instructional Practices } & \multicolumn{2}{|c|}{$\begin{array}{ll}\text { df } & \text { Pearson Chi-Square }\end{array}$} \\
\hline & \multicolumn{3}{|c|}{ Cooperative Learning } & \multirow{4}{*}{2} & \multirow{4}{*}{$\begin{array}{c}18.000 \\
p=.000\end{array}$} \\
\hline & count & No & Yes & & \\
\hline & Observed & 4 & 20 & & \\
\hline & Expected & 5.3 & 18.7 & & \\
\hline & Rich Voca & lary & & \multirow{3}{*}{2} & \multirow{3}{*}{$\begin{array}{l}6.503 \\
p=.039\end{array}$} \\
\hline \multirow{2}{*}{ Oligarchic } & Observed & 6 & 22 & & \\
\hline & Expected & 3.3 & 20.7 & & \\
\hline \multirow{2}{*}{ Anarchic } & Reinforcen & & & \multirow{3}{*}{2} & \multirow{3}{*}{$\begin{array}{l}7.510 \\
p=.010\end{array}$} \\
\hline & Observed & 0 & 24 & & \\
\hline \multirow{2}{*}{ Internal } & Expected & 2.0 & 22.0 & & \\
\hline & Simulatior & & & \multirow{3}{*}{2} & \\
\hline \multirow{5}{*}{ External } & Observed & 0 & 24 & & 37.895 \\
\hline & Expected & 5.0 & 19.0 & & $\mathrm{P}=.000$ \\
\hline & Daily Asse & ment & & \multirow{3}{*}{2} & \multirow{3}{*}{$\begin{array}{l}14.500 \\
p=.039\end{array}$} \\
\hline & Observed & 4 & 23 & & \\
\hline & Expected & 2.7 & 21.3 & & \\
\hline
\end{tabular}

Source: Authors' Own Work

Table 6 reveals the:

\section{Relationship between (TSPT-III) and (IP) Cooperative Learning}

$\chi^{2}=18.000, \mathrm{df}=2, \mathrm{p}=.000$. It indicates that the $\mathrm{p}$-value is less than $\alpha=.05$ i.e. there is a significant relationship between all (TSPT-III) and Cooperative Learning as (IP). Thus rejecting the null hypothesis i.e. there is no significant relationship between (TSPT-III) and observed (IP) Cooperative Learning.

\section{Relationship between (TSPT-III) and (IP) Rich Vocabulary}

$\chi 2=6.503, \mathrm{df}=2, \mathrm{p}=.039$. It indicates that the $\mathrm{p}$-value is less than $\alpha=.05$ i.e. there is a significant relationship (TSPT-III) and Rich Vocabulary as an (IP). Thus rejecting the null hypothesis i.e. there is no significant relationship between (TSPT-III) and observed (IP) Rich Vocabulary.

\section{Relationship between (TSPT-III) and (IP) Reinforcement}

$\chi 2=3.273, \mathrm{df}=2, \mathrm{p}=.010$. It indicates that the $\mathrm{p}$-value is less than $\alpha=.05$ i.e. there is a significant relationship (TSPT-III) and Reinforcement as an (IP). Thus rejecting the null hypothesis i.e. there is no significant relationship between (TSPT-III) and observed (IP) Reinforcement.

\section{Relationship between (TSPT-III) and (IP) Simulations}

$\chi 2=37.895, \mathrm{df}=2, \mathrm{p}=.000$. It indicates that the $\mathrm{p}$-value is less than $\alpha=.05$ i.e. there is a significant relationship between (TSPT-III) and Simulations as an (IP). Thus rejecting the null hypothesis i.e. there is no significant relationship between (TSPT-III) and observed (IP) Simulations.

\section{Relationship between (TSPT-III) and (IP) Daily Assessment}

$\chi^{2}=4.500, \mathrm{df}=2, \mathrm{p}=.002$ indicates that the $\mathrm{p}$-value is less than $\alpha=.05$ i.e., there is a significant relationship between (TSPTIII) and Daily Assessment as an (IP). Thus, rejecting the null hypothesis i.e. there is no significant relationship between (TSPT-III) and observed (IP) Daily Assessment.

\section{DISCUSSION}

The results revealed that the teachers were identified into three (TSPT-I, II, and III). The results showed that the set of dominating (IPs) used by the teachers of (TSPT-I) comprised of Concept Accomplishment, Simulations, Cooperative Learning, Homework, and Reinforcement. The further showed that the set of dominating (IPs) used by the teachers of (TSPT-II) consisted of Rich Vocabulary, Lecturing, Daily Assessment, Concept Accomplishment, and Reinforcement. And 
dominating (IPs) used by the teachers of (TSPT)-III were cooperative Learning, Rich Vocabulary, Reinforcement, Simulations, and Daily Assessment.

Moreover, the results also revealed that there was an association between (IPs) i.e., Concept Accomplishment, Simulations, Cooperative Learning, Homework, and Reinforcement and teachers of (TSPT-I) showing the teachers of (TSPT-I) preferred the instructional practices having creativity, critical thinking higher order of degree of freedom, innovative decision making, conceptual cadence, field-independent native personality, and artistic nature and have artistic nature. The studies by (Vermunt, 2014; Mushtaq, 2013) also show that the change in the attitudes of the teachers and affects their professional development of the teacher.

The result further revealed that there was a significant association between (IPs) i.e. Rich Vocabulary, Lecturing, Concept Accomplishment, Formative Assessment, and Reinforcement and teachers of (TSPT-II). It shows the teachers having lower creativity and cognitive complexity preferred traditional ways of processing required information respect authority and follow given instruction. Moreover, the results further reported a significant association between (IPs) i.e., Cooperative Learning, Rich Vocabulary, Reinforcement, Simulations, and Daily Assessment and the teachers of (TSPT-III).it shows that the teachers of (TSPT-III) preferred social, realistic integrative and investigative thinking, abstract random and sequential style with extrovert personality. The studies by (Devine, Fahie, \& McGillicuddy, 2013; Zhang \& Sternberg, 2005) support the results that the teacher of (TSPT-III) preferred instructional practices having different contexts and change simultaneously. These results revealed the interest and skills of the teachers (TSPT-I, II, and III) for certain sets of IPs) at the secondary school level. The Empirical studies by (Yang \& Lin, 2004; Song, 2017) reported that there was a relationship between thinking styles and instructional practices i.e., classroom dialogue, creative, critical thinking, and thinking styles.

\section{CONCLUSION}

Based on the findings of the study it is concluded that there was a relationship (TSPT-I, II, and III) for certain sets of IPs) used by the teachers at the secondary level. Teachers of (TSPT-I) preferred using Concept Accomplishment, Simulations, cooperative Learning, Homework, and Reinforcement as a set of instructional practices in the classroom at the secondary school level. As a lot of resources are wasted on the general training programs, the teacher trainers may design the programs focusing on the preferences of the teachers and safe time and money wasted on the general training of the teachers. Further, it is also concluded that teachers of (TSPT-II) preferred Rich Vocabulary, Lecturing, Daily Assessment, Concept Accomplishment, and as instructional practices. Moreover, the teachers of the (TSPT-III) preferred Cooperative Learning, Rich Vocabulary, Reinforcement, Simulations, and Daily Assessment as instructional practices in the classroom at the secondary school level. The teachers may be grouped into (TSPT-I, II, and III) and train according to their preference for certain sets of instructional practices.

\section{RECOMMENDATIONS}

The following recommendation was generated from the findings of the study:

Teacher trainers and teacher training organizations may strengthen and focus on the preferred set of (IPs): Concept Accomplishment, Simulations, cooperative Learning, Homework, and Reinforcement for the teacher having (TSPT-I). They may also focus and strengthen the preferred set of (IPs): Rich Vocabulary, Lecturing, Daily Assessment, Concept Accomplishment, for the teacher having (TSPT-II) and they may strengthen and focus on the preferred set of (IPs): Cooperative Learning, Rich Vocabulary, Reinforcement, Simulations, and Daily Assessment for the teacher having (TSPTIII) while designing and conducting teachers' training programs for in-service teachers.

\section{AUTHORS' CONTRIBUTION}

\section{Corresponding Author:}

Abdul Qayyum is a Ph.D. scholar and this research article is based on his Ph.D. research thesis.

\section{Second Author:}

Dr. Sidra Rizwan is my co-supervisor. She has guided me throughout my research project particularly in this article she has thoroughly reviewed it and guided me throughout the process.

\section{Third Author:}

Dr. Nasir Mahmood is my Supervisor in Ph.D. and I have completed my Ph.D. research thesis under his supervision. 


\section{REFERENCES}

1. Budijanto, R, R (2013). Thinking Styles, Teamwork Quality, and Performance. Un published doctoral thesis. The University of Canberra. Australia.

2. CTAC \& WCS (2015). Instructional practices list. Community Training and Assistance Center and Washoe County School District. New York: Reno.

3. Curry, L. (1983). An organization of learning styles theory and constructs. ERIC Doc. 235:185.

4. Devine, D., Fahie, D., \&McGillicuddy, D. (2013). What is "good" teaching Teacher beliefs and practices about their teaching? Irish Educational Studies, 32(1), 83-108. https://doi.org/10.1080/03323315.2013.773228

5. Fer, S. (2012). Demographic Characteristics and Intellectual Styles. In Handbook of Intellectual Styles Preferences in Cognition, Learning, and Thinking. Springer. The USA.

6. Hayes, A. F., \& Krippendorff, K. (2007). Answering the call for a standard reliability measure for coding data. Communication Methods and Measures, 1, 77-89. https://doi.org/10.1080/19312450709336664

7. Ho, L.M \&Maroof, N. (2009). Thinking Styles of Teacher Trainees in Four Teacher Training Institutes in Malaysia. International Journal of Learning.16 (8), 473-484. https://doi.org/10.18848/1447-9494/CGP/v16i08/46533

8. Hussain, I., Reddy, Y., \& Kamil, M S. (2018). Governing the ungovernable. Retrieved on May 6, 2021 from http://www.yvreddy.com/wp-content/uploads/2018/06/Governing-the-Ungovernable.pdf.

9. King, S. H., \& Watson, A. (2010). Teaching excellence for all our students. Theory Into Practice, 49, 175-184. https://doi.org/10.1080/00405841.2010.487751

10. Marzano, R. J., \& Pickering, D. J. (2007). The case for and against homework. Educational Leadership, 64(6), 7479.

11. Medwel, J and Wray, D (2018). Primary homework in England: the beliefs and practices of teachers in primary schools. Research gate, Education 3-13. https://doi.org/10.1080/03004279.2017.1421999

12. Miller, A. (1987). Cognitive Styles: an integrated model. Educational Psychology, 7(4), 251268. https://doi.org/10.1080/0144341870070401

13. Mushtaq, M. (2013) The Changes and Challenges of Secondary Level Teachers Education in Pakistan: A Training Perspective. International Journal of Academic Research in Business and Social Sciences, 3(12). https://doi.org/10.6007/IJARBSS/v3-i12/422

14. Ribas, W.B. (2005). Instructional Practices that Maximise Student Achievement: For teachers, By teacher.: The USA. Ribas Publications.

15. Riding, R., \& Cheema, I. (1991). Cognitive styles-An overview and integration. Educ. Psychol. 11(3 \& 4): 193215.

16. Riding, R. J., and Rayner, S. (1998). Cognitive Styles and Learning Strategies: Understanding Style Differences in Learning and Behavior, David Fulton, London.

17. Song, Y. (2017). An Investigation of the Relationships between Thinking Style, Participation in Classroom Dialogue and Learning Outcomes - A Study based in Mainland China.(Unpublished doctoral dissertation). University of Cambridge, Cambridge, UK.

18. SRC (2011). Powerful instructional practices. Stewart Resources Centre Saskatchewan Teachers' Federation, SK. CA.

19. OECD (2015). Teaching Belief and Practice, retrieved from www.oecd.org/talis in May 2019.

20. Sternberg, R. (1997). Thinking style profiles. Cambridge: Cambridge University Press.

21. Sternberg, R.J., Wagner, R.K., \& Zhang, L.F. (2007). Thinking style profiles inventory - Revised II. Unpublished test, Tufts University.

22. Vermunt, J. D. (2014). Teacher learning and professional development. In S. Krolak-Schwerdi et al. (Eds.), Teachers' Professional Development (pp. 79-95). Brill Sense. https://doi.org/10.1007/978-94-6209-536-6_6

23. Watson, M. B., Foxcroft, C. D., \& Allen, L. J. (2007). Tracking Holland Interest codes: The case of South African field guides. Australian Journal of Career Development, 16(2), 51-59. Retrieved from ERIC. https://doi.org/10.1177/103841620701600208

24. Yang, S., \& Lin, W. (2004). The Relationship Among Creative, Critical Thinking and Thinking Styles in Taiwan High School Students. Journal of Instructional Psychology, 31(1), 33-45.

25. Zhang, L.F.\&Postiglione, G (2001). Thinking styles, Self- Esteem and socio-Economic Status. Personality and Individual Differences, 31(2001), 1333-1346. https://doi.org/10.1016/S0191-8869(00)00227-0

26. Zhang, L.F. (2003). Are parents' and children's thinking style profiles related? Psychological Reports, 93(2), 617630. https://doi.org/10.2466/pr0.2003.93.2.617

27. Zhang, L.F., \&Sternberg, R.J. (2005). A Threefold Model of Intellectual Styles. Educational Psychology Review, 17(1). https://doi.org/10.1007/s10648-005-1635-4 
Humanities \& Social Sciences Reviews elSSN: 2395-6518, Vol 9, No 3, 2021, pp 372-383 https://doi.org/10.18510/hssr.2021.9338

28. Zhang, L.F. (2016). Is inquiry-based science teaching worth the effort? Science \&Education, 25, 897-915. https://doi.org/10.1007/s11191-016-9856-0

29. Zhu, C. (2013). Students' and Teachers' Thinking Styles and Preferred Teacher Interpersonal Behavior. The Journal of Educational Research, 106:5, 399-407. https://doi.org/10.1080/00220671.2012.736431 